\title{
EDUCATION POLICY AND EFFECTIVENESS OF THE PLAGIARISM DETECTION SYSTEM
}

\author{
VANO TSERTSVADZE \\ PhD, Professor \\ Georgian Institute of Public Affairs (GIPA), Georgia \\ v.tsertsvadze@gipa.ge
}

\section{LALI KHURTSIA}

\section{Doctor of Economics, Assistant Professor}

Ivane Javakhishvili Tbilisi State University, Georgia

lali.khurtsia@tsu.ge

Abstract. In 2018, 13 Georgian Universities have implemented Plagiarism Detection and Prevention Program (PDPP) within the framework of the EU-supported project. This process establishes favorable conditions for the study of students' behavior, incentives and the use of plagiarism in pre-PDPP era and after its implementation. To prove the significance impact of the PDPP on academic honesty and to assess the system for effectiveness we use statistical tests. The experience observed in western universities confirms that the existence of PDPP is correlated with the reduction of plagiarism. Though, the effective application of PDPP entirely depends on the efforts of Georgian universities to pursue anti-plagiary policy. Along with the policy analysis, plagiarism perceptions and attitudes have been studied in accordance with historical and cultural environment. The research also analyses the study in the paradigm of risk and benefit from students point of a view as a decision-making process (weighing probability of detection and penalty size and positive mark).

\section{KEYWORDS: PLAGIARISM, ACADEMIC HONESTY, TURNITIN, CHEATING, CITING, UNIVERSITY, ACADEMIC WRITING, RISK, BENEFIT}

For citation: Tsertsvadze, V., Khurtsia, L. (2020), Education policy and effectiveness of the plagiarism detection system. Globalization and Business, №9, pp. 151-155 https://doi.org/10.35945/gb.2020.09.018

\section{INTRODUCTION}

The problem of plagiarism is quite serious in the education system of the modern world. The countries with great scientific traditions are successfully using information technologies to solve this problem. In 2018, piloting of the Plagiarism Detection and Prevention Program was launched in the high educational institutions of Georgia with the EU support.

Unfortunately, there have been almost no studies in this field in Georgia so far and, therefore, research-based discussions on plagiarism are quite rare in Georgian scientific literature. In practice, there are only a few cases of the court proceedings regarding copyright, which have financial grounds.

Currently, there are 52 accredited high educational institutions in Georgia, at which about 100,000 Bachelor, Master and Doctoral students are studying every year, approximately 17000 persons graduate from the high educational institutions and defend their academic degree with the relevant quantity of topics. Due to the absence of the data on plagiarism and the plagiarism detection systems in Georgia before 2018, checking these papers for authenticity was a very time-consuming task, as it required a great deal of time and human resources. Nonexistence of the plagiarism detection system had negative impact on the quality of learning process and its outcomes.

Our goal is to study the use of plagiarism in the Georgian education system, to identify the motives thereof and the expectations, methods and ways applied by the students in the process of working on their papers. The results of the study will enable us to determine a preventive policy approach in general, which will reduce the use of plagiarism and raise the level of scientific studies in the country.

\section{LITERATURE ANALYSIS}

In the literature analysis, we tried to discuss the problem of plagiarism as the risk/benefit decision-making process, taking into consideration the cultural and historical factors affecting it.

In a broad sense, plagiarism is the use of other authoris opinions and/or ideas without the reference to the author. There are four different types of student plagiarism: taking the material from various sources, including by purchasing the prepared paper from the appropriate service provider (1), 
total appropriation of the work written by another person (2), copying different parts of other works in the own work (3), paraphrasing without the reference to the respective source (4). (Park 2003). In our study, we took into consideration all the above-mentioned types of student plagiarism and examined the cases of purchasing the prepared papers and the wrongful use of others' opinions.

Earlier studies of student plagiarism were carried out in English-speaking countries. A large-scale study carried out in 1964, in which 5000 students from different universities of the USA participated, established that $75 \%$ of students had at least once used plagiarism in their papers (Bowers, 1964). This study became the basis for many other studies in the field of plagiarism. Modern studies are increasingly focused on the aspects of plagiarism, such as the influence of stimulating, motivating ((Stevens and Stevens. 1987), (Davis at all. 1992), (Love and Simmons. 1998), (Park 2003), (Owens and White. 2013)) and institutional factors on the student's decision to use plagiarism ((McCabe 1992), (McCabe and Trevino 1993, 1997, 2001)).

Stimulating factors include the motives, such as, on the one hand, unintentional plagiarism (e.g. lack of knowledge of citation rules) and, on the other hand, intentional stimulating factors, such as getting a better score, an uninteresting course, pressure from the peers or parents, disobedience or disrespect to administration. Institutional factors include the existence of the regulating rules, which determine sanctions for the dishonest preparation of papers, and the seriousness of the penalty for academic fraud. In this regard, it is noteworthy that the study performed with the participation of 6000 students of high educational institutions has established that the existence of university regulations in the area of plagiarism significantly affect the frequency of academic frauds in the teaching process (McCabe, and Trevino. 1993).

Since the 1990s, several studies were carried out in different countries on the issue of attitude to risks in the cultural context ((Davis et all 1994), (Waugh et all 1995), (Burns et all 1998), (Lim, and Sean 2001)).

These studies proved that the students) attitude towards plagiarism in the cultural context significantly varies depending on their nationality and cultural background. In this respect, the comparison of the results of only western studies with the Georgian environment would represent only one side of the problem. In this regard, it is important and noteworthy that geographically Georgia is located on the border of European and Islamic cultures. Historically, this location has significantly shaped Georgian culture and character, including the attitude towards the use of plagiarism. According to the modern western culture, a human is a source of knowledge. A human is the rightful owner of his/her knowledge and he/she has a complete right to earn financial benefit from that knowledge (Stearns, 1999). As for the eastern, namely Islamic world, it is considered that knowledge is the blessing gifted by the God, thus, it must be shared and not monopolized. Muslim scholars acquire knowledge in a verbal form and then pass that knowledge to others, adding their own interpretations. In addition, appreciation is given to the initial source of knowledge. In such an environment, the issue of recognition of plagiarism is not raised (Moten. 2014). It is an inherent feature for the eastern culture that people copy the papers of their friends and the authors they know. Due to those relations, such action is not considered as plagiarism (Tayraukham 2009).

It should be mentioned that Georgian culture partially shares that eastern influence. Persian and Greek myths and legends were an important source of Georgian folklore. One of the most ancient and popular legends of them is the legend of Amirani, the Georgian Prometheus. (Gugunava 2012).

Persian literature has also greatly influenced Georgian literature. Ivane Javakhishvili, a Georgian historian, notes that although 'Shahnameh' (Rostomiani) by Ferdowsi, 'Visramiani', 'Kalila and Demna', 'Layla and Majnun' were written by Persian Muslim poets, they were read by Christian Georgians with great affection, as those works were valuable treasure of literature for them. Besides, Georgian secular poetry was revived by the influence of Persian literature. (Javakhishvili, 1965, pp. 305-306).

In the literature review, we should also consider the nearest historical context, which influences the attitude towards various issues, including plagiarism, in Georgia. The fact that Post-Soviet states face similar problems is proved by the studies, carried out in the former Soviet republics, most part of which is dedicated to the corruption at higher educational institutions of the Post-Soviet region ((Antonovich and Merezhko. 2006), (Osipian, 2009), (Osipian, 2010). (Podolyan 2006), (Taksanov, 2003)).

The corruption systems existing in the higher educational institutions of the Post-Soviet states led to the formation of informal businesses, which offer students, for a certain fee, the prepared papers for obtaining Bachelor's, Masteris and doctoral degrees.

The demand on that informal market is produced by the Bachelor's and Master's degree students, who buy course works and theses, and the supply is provided by different companies offering respective services to the students in the form of prepared papers.

Such an informal market exists in Georgia as well, where students are able to find and purchase prepared course works and theses from the appropriate agents. Since there is a demand, there is always a supply, and in Georgian internet sources there are the websites, through which the students' papers are sold.

In 2016, the only study on plagiarism was carried out in Georgia, the purpose of which was to examine the policy and practice related to and the attitudes towards plagiarism in Georgia, which revealed the motivational and institutional factors of the problem (Ghlonti et al., 2016).

Despite the lack of such studies in Georgia, in order to reduce the magnitude of academic fraud, in 2018 the pilot Turnitin programme for the detection and prevention of plagiarism was launched in Georgia. So far, a little time has elapsed from the introduction of the programme and, thus, there are not any reliable data on whether these preventive measures had any impact on reducing plagiarism or not. We are keeping an eye on that issue and we are currently collecting the data. In the present study, we focus on the demand/supply 
sides of the informal market in Georgian education system and the main operating impulses on that market.

\section{RESEARCH METHODOLOGY}

The study consisted of the surveys carried out in several target groups.

The first of them included students. This group determines demand and represents the client of the supply side. A study was carried out with this group, which comprised the students of the Bachelor's and Master's programmes of the Georgian Institute of Public Affairs and Tbilisi State University $(n=120)$.

Within the scope of our study, we needed an additional target group survey, as the research process required an additional answer to the question: 'Does the problem of plagiarism have cultural roots in Georgia?' In order to answer the question, we interviewed the professors engaged in the university processes. One focus group was organised, in which the representatives of different universities, the professors of humanities and technical fields, and the psychologists took part. The goal of the focus group was to determine whether there is any connection between the Soviet era education system and the learning process of the education system of modern Georgia.

\section{RESEARCH RESULTS}

$60 \%$ of respondents (72 students) stated that they had at least once 'borrowed' another person's text without making-reference to the source of the text, or used the paper written by another person. $2.5 \%$ of them stated that they have applied to another person to write their papers.

As we asked students about their personal involvement in the process of plagiarism, we were also interested to what extent and how often are their peers involved in the process of plagiarism. The data obtained, i.e. other information about other students' involvement in the academic fraud, was consistent with and even slightly exceeded the students) responses, which were based on their personal experience. $62 \%$ of respondents stated that the people around them often use plagiarism (often means using plagiarism at least once during the semester), $33 \%$ of the respondents stated that the people around them permanently use plagiarism (permanently means that most part of the writing assignments are performed with the use of plagiarism).

The interviews showed that, in most cases, students deliberately tried to use other authors' papers as their own. The answers to the question: 'What was a key motivating factor for you?' were distributed as follows (out of the answers of those 72 respondents who stated that they had committed academic fraud at least once): when during the studies the student committed academic fraud: 'What was a motivating factor for you when you were working on your paper with this method?' the answers of 60 respondents were distributed as follows: $20 \%$ of respondents (14 out of 72 students) - they did so in order to get a good evaluation, $60 \%$ of them (43 students) found it easy to use plagiarism
- using plagiarism was easier, 18\% (13 students) was not interested in the subject, and 2 students stated that they used plagiarism because their parents expected them to get good evaluation (2\%).

In addition, the results of the interviews appear to support our hypothesis on the impact of the risk of detection and seriousness of penalties on using plagiarism; as for the motive, we additionally asked the students to evaluate the chance of detection of the 'borrowing' and the measure of punishment for such an action. In this regard, absolutely all respondents answered that the cases of detection of plagiarism and the sanctions imposed on them are so insignificant that it may even be a certain motivating factor for using plagiarism. All the persons, except for one, who have ever used such method for preparing their papers, stated that the violation had never been detected.

We asked the students, who were caught in plagiarism, about the sanctions that were imposed on them for the violation. The answer was that the students were required to write the paper again.

The main decisive factor in this case is the low detection rate in the total number of papers, which is caused by the fact that universities have not used the plagiarism detection system so far. In most cases, universities used so-called 'googling', i.e. the Google search engine to check the originality of a student's paper. This method is ineffective when students use texts translated from a foreign language and when students copy the text from the materials, which are not available online. Thus, one of the main findings of our study is that even in those rare cases when plagiarism was detected, the students had to write their papers again or to retake the exam. The respondents stated that the absence of the specialized plagiarism detection system and the penalties of inappropriate severity in the case of fraud create an additional stimulating factor for fraud.

\section{FOCUS GROUP AND DISCUSSION}

In order to explain this phenomenon, we additionally addressed a focus group comprising the lecturers of different subjects and the psychologists. Our main goal was to find out if the problem of plagiarism has cultural and historical grounds in Georgia.

The focus group noted that, at present, the problem of plagiarism starts from the school years. Secondary school students copy assignments from one another. In order to cover up an attempt to copy, they rearrange the issues included in the text. It is quite a common method. So-called 'cheat sheets' are actively used as well. Thus, the behaviour of falsifying oness own work develops at a school age.

Such behaviour may be caused by the fact that avoiding fulfillment of assignments fairly and avoiding the teaching rules is some kind of fashion. Rules, teachers, lecturers are the boundaries for the pupils and students that must be overstepped. For many pupils disregarding rules is a subject of excitement of their peers, which may be one of the motivating factors for such a behaviour.

In this case, the learning process is considered by pupils 
(and not only by pupils, teachers may have the same attitude as well) as the confrontation between two antagonistic parties. One party is the administration of a school or university, which establishes the rules of conduct for the second party, pupils and students. Historically, such attitude may be traced back in the past. From the Middle Ages to the end of the 20th century, as a result of enemy invasions Georgia was governed by the rules of people who were different in terms of tribes and culture. Constant resistance to foreign laws was the only means for maintaining national image. There are many examples in the history of Georgia on heroic disobedience and on persevering fight against the enemy. These examples were first used verbally and then in writing, and, at present, they are the most enjoyable stories for Georgian children. Thus, disobedience is an inherent feature of Georgian consciousness that is formed from the early childhood.

After the annexation of Georgia by Russia in 1801, disobedience continued. In the conditions of Communist ideology, that resistance moved to the area of education as well. The case is that Communist education system was much ideologized. Almost all subjects, except for technical subjects, were full of the materials of meetings of the Communist Party and Lenin's quotes. The exams in such subjects were passed by bribing lecturers or by falsification of the papers.

It would be interesting to review the findings from the standpoint of crime economics. When do people commit crime? People commit crime when the benefits of crime are higher than the risks of being caught or found guilty. Plagiarism can also be explained from this standpoint. If a student feels that the risk of being caught is close to zero and his/her paper will not be caught in fraud, he/she uses plagiarism.
However, at the same time, besides the likelihood of detection of an academic offence, a student also takes into account the severity of the punishment that may be imposed on him/her if he/she is caught. The decision dilemma is as follows: What will be the follow-up measures if plagiarism is confirmed in his/her paper? Will he/she have to write the paper again or retake the exam, or will he/she be immediately expelled from university? If the punishment is too low, the student will still have the motive to use plagiarism.

The results of our study showed that $60 \%$ of the interviewed students uses plagiarism, and the plagiarism was detected only in one case, the punishment for which was that the student had to write the paper again.

\section{CONCLUSION}

Based on the presented analysis, the following deductions may be made:

The problem of plagiarism in Georgia may be of cultural and mental nature.

The perceptions of plagiarism in students is contradictory, on the one hand, they use plagiarism and, on the other hand, they realize that plagiarism is unethical and illegal.

In our opinion, removing the barriers that still exist between the lecturer and the student in the education system, and the understanding of the principles of fair learning process among the pupils and students should be the main task of these past years.

In the case of plagiarism, students analyze the problem of making-decision between the expected benefits and the likelihood of possible sanctions.

\section{REFERENCES}

Park, Chris. (2003). "In Other (People's) Words: Plagiarism by University Students - Literature and Lessons." Assessment and Evaluation in Higher Education 28(5): 471-488.

Bowers, William J. (1964). Student Dishonesty and its Control in College. New York: Columbia University

Stevens, George E., and Faith W. Stevens. (1987). "Ethical Inclinations of Tomorrow's Managers Revisited: How and Why Students Cheat." Journal of Education for Business 63(1): 24-29.

Davis, Stephen F., Cathy A. Grover, Angela H. Becker, and Loretta N. McGregor. (1992). "Academic Dishonesty: Prevalence, Determinants, Techniques, and Punishments." Teaching of Psychology 19(1): 16-20.

Love, Patrick G., and Janice Simmons. (1998). "Factors Influencing Cheating and Plagiarism Among Graduate Students in a College of Education." College Student Journal 32(4): 539-550.

Park, Chris. (2003). "In Other (People's) Words: Plagiarism by University Students - Literature and Lessons." Assessment and Evaluation in Higher Education 28(5): 471-488.

Owens, Caleb, and Fiona A. White. (2013). "A 5-year Systematic Strategy to Reduce Plagiarism Among First-Year Psychology University Students." Australian Journal of Psychology 65(1): 14-21.

McCabe, and Donald L. (1992). "The Influence of Situational Ethics on Cheating Among College Students." Sociological Inquiry 62(3): 365-374.

McCabe, Donald L., and Linda K. Trevino. (1993). "Academic Dishonesty: Honor Codes and Other Contextual Influences." The Journal of Higher Education 64(5): 522.

McCabe, Donald L., and Linda K. Trevino. (1997). "Individual and Contextual Influences on Academic Dishonesty: A Multicampus Investigation." Research in Higher Education 38(3): 379-396.

McCabe, Donald L., Linda K. Trevino, and Kenneth D. Butterfield. (2001). "Cheating in Academic Institutions: A Decade of Research." Ethics and Behavior 11(3): 219-232. 
Davis, Stephen F., Linda M. Noble, Elizabeth N. Zak, and Kristen K. Dreyer. (1994). “A Comparison of Cheating and Learning/ Grade Orientation in American and Australian College Students." College Student Journal 28: 353-356.

Waugh, Russell. F., John R. Godfrey, Ellis D. Evans, and Delores Craig. (1995). “Measuring Students' Perceptions about Cheating in Six Countries." Australian Journal of Psychology 47: 73-80.

Burns, Susan R., Stephen F. Davis, Janice Hoshino, and Richard L. Miller. (1998). "Academic Dishonesty: A Delineation of CrossCultural Patterns." College Student Journal 32: 590-596.

Lim, Vivien K. G., and Sean K. B. See, (2001). "Attitudes Toward, and Intentions to Report, Academic Cheating Among Students in Singapore." Ethics and Behavior 11(3): 261-274.

Abdul Rashid Moten. Academic dishonesty and misconduct: Curbing plagiarism in the Muslim world. Intellectual Discourse, 22:2 (2014) 167-18, Copyright (C) IIUM Press ISSN 0128-4878 (Print); ISSN 2289-5639 (Online).

Tayraukham, S. (2009). Academic ethics in research methodology. The Social Sciences, 4(6), 573-577.

Maia Gugunava. Translations from Georgian into Spanish, from 1970 to the present. (2012). https://www.google.ge/url? sa=t\&rct=j\&q=\&esrc=s\&source=web\&cd=4\&cad=rja\&uact=8\&ved=0ahUKEwibwrqbjdvLAhXGuRQKHca4CuMQFggvMA M\&url=http\%3A\%2F\%2Fwww.bookplatform.org\%2Fimages\%2Factivities\%2F364\%2Fgeorgiantospanishtranslationsstu dy_ge1.doc\&usg=AFQjCNHcY2M3yT4gorwzaJPfkz9jPaP58Q (In Georgian)

Antonovich, Miroslava, and Oleksandr Merezhko. (2006). "Yak podolati koruptsiju" [in Ukrainian]. October 27. http://gazeta. dt.ua/EDUCATION/yak_podolati_koruptsiyu.html. (Accessed December 29, 2016).

Osipian, Ararat. (2009). "Corruption and Reform in Higher Education in Ukraine." Canadian and International Education 38(2): 104-122.

Osipian, Ararat. (2010). "Dissertations for Sale: Corruption in Russia's Doctoral Education." Presented at the Annual Meeting of the American Economic Association, Atlanta. https://www.aeaweb.org/conference/2010/retrieve. php?pdfid=88. (Accessed December 29, 2016).

Podolyan, Lidia. (2006). "Chi mozhlivij ukrains'kij ekvivalent PhD, abo yak unemozhliviti kupivlju disertatsii” [in Ukrainian]. Dzerkalo tyzhnya, October 19. http://www.osvita.org.ua/articles/138.html. (Accessed December 29, 2016).

Taksanov, Alisher. (2003). "Yavlenie korruptsii v Uzbekistane" [in Russian]. CentrAziya, May 3.

V Tsertsvadze, L Khurtsia, Y Krylova. (2017). Student Plagiarism in Georgia> Higher Education. Ongoing Issues in Georgian Policy and Public Administration, 79-94 